\title{
GERMINAÇÃO DE TRIGO INOCULADO COM Azospirillum brasilense SOB DISTINTOS pH's DA ÁGUA DE EMBEBIÇÃO
}

\author{
Marlo Adriano Bison Pinto ${ }^{1}$, Ubirajara Russi Nunes², Glauber Monçon Fipke ${ }^{3}$ \\ ${ }^{1}$ Doutorando em Agronomia, Centro de Ciências Rurais, Universidade Federal de Santa Maria, Santa Maria, \\ RS. E-mail: marlo.bison@gmail.com \\ ${ }^{2}$ Professor Doutor do Departamento de Fitotecnia, Universidade Federal de Santa Maria, Centro de Ciências \\ Rurais, Santa Maria, RS. \\ ${ }^{3}$ Doutorando em Agronomia, Centro de Ciências Rurais, Universidade Federal de Santa Maria, Santa Maria, \\ RS.
}

RESUMO: O objetivo do trabalho foi avaliar a qualidade fisiológica de sementes de trigo submetidas a inoculação com a bactéria fixadora de azoto Azospirillum brasilense, estirpes $\mathrm{Ab}-\mathrm{V}_{5}$ e $\mathrm{Ab}-\mathrm{V}_{6}$, em função do $\mathrm{pH}$ da água de embebição. Para tal, avaliou-se a germinação das sementes do trigo e a atividade da bactéria durante o desenvolvimento inicial de plântulas. O estudo foi desenvolvido em condições de laboratório, com delineamento inteiramente casualizado, com arranjo fatorial 2x2x2 (lote, inoculação e pH da solução de embebição), com oito repetições. Para avaliação da qualidade fisiológica utilizaram-se os testes de germinação, primeira contagem da germinação, comprimento da radícula e da parte aérea e massa seca de plântulas. A germinação não foi influenciada pelo fator $\mathrm{pH}$ da água de embebição. Sementes inoculadas com A. brasilense apresentaram menor percentual de germinação. Houve resposta distinta entre lotes. Sementes do lote um apresentaram maior vigor com bactéria. A presença da bactéria não agregou efeito sobre vigor das sementes provenientes do lote dois. A inoculação com A. brasilense reduz o percentual de germinação de sementes de trigo. $\mathrm{O}$ pH neutro da água de embebição reduz os efeitos resultantes da variação de vigor entre lotes.

Palavras-chave: Crescimento inicial. Inoculação. Triticum aestivum L.

\section{GERMINATION OF WHEAT SEEDLINGS INOCULATED WITH Azospirillum brasilense AT DIFFERENT pH's OF WATER}

\begin{abstract}
The objective of the work it was to evaluate the physiological quality of wheat seeds submitted to inoculation with Azospirillum brasilense, estirpes Ab-V5 end AbV6, depending on the $\mathrm{pH}$ of the imbibition water. For this, the germination of the wheat seeds and the activity of the bacterium during the initial development of seedlings were evaluated. The study was developed under laboratory conditions, with a completely randomized design, with a $2 \times 2 \times 2$ factorial arrangement (lote, inoculation and $\mathrm{pH}$ of the imbibition solution), with eight replications. For the evaluation of the physiological quality, germination, first germination, root and shoot length and seedling dry mass tests were used. Germination was not influenced by the $\mathrm{pH}$ of the imbibition water. Seeds inoculated with $A$. brasilense presented lower percentage of germination. There is a distinct response among
\end{abstract}

Cultura Agronômica, Ilha Solteira, v.26, n.4, p.694-704, 2017 
cultivars. Seeds of lot 1 showed greater vigor with bacteria. The presence of the bacteria had no effect on the vigor of the seeds coming from lot 02. A seed inoculation with A. brasilense reduces the germination percentage of wheat seeds. The neutral $\mathrm{pH}$ of the water reduced the effects resulting from the vigor variation between seeds.

Key words: Inoculation. Seedling growth. Triticum aestivum L.

\section{INTRODUÇÃO}

O trigo é um dos alimentos mais utilizados para alimentação humana (SILVA et al., 2015). Incrementar a sua produtividade pode, além do atendimento à demanda nacional, garantir o fluxo econômico e a sustentabilidade das propriedades rurais (BARBIERI et al., 2013; SILVA et al., 2015).

Por si só, o melhoramento genético aliado a utilização de práticas culturais eficientes, podem ser ineficazes se a qualidade das sementes for fator limitante no processo produtivo (FAVARATO et al., 2012). Sob condições de campo as sementes de trigo são normalmente expostas a vários fatores de estresse, tais como: salinidade, temperatura e pH da solução do solo inadequados (CARVALHO; KRZYZANOWSKI, 2012; REIS et al., 2014). A água é um dos principais fatores externos que atua na ativação de diferentes processos metabólicos envolvidos na germinação de sementes, o que pode reduzir ou manter o vigor inicial das plântulas, limitando o potencial genético da cultura (ALMEIDA et al., 2011). Assim, a utilização de tecnologias que promovam o crescimento é indispensável; principalmente sob condições desfavoráveis para a germinação e o crescimento de plântulas.

Dentre as alternativas disponíveis para obtenção de plântulas superiores, a associação das sementes com bactérias diazotróficas pode ser uma alternativa (PEREIRA et al., 2017). A capacidade destes microrganismos em estimular o crescimento de plantas envolve mecanismos de conversão enzimática do nitrogênio gasoso em amônia e a produção de fitohormônios (BERGAMASCHI et al., 2007).

Dentre estes fitohormônios estão auxinas, giberilinas e citocininas que podem alterar o percentual germinativo das sementes e a marcha de divisão celular, de modo que em quantidades apropriadas estimulam a germinação, a densidade e o comprimento de pelos radiculares, assim como a taxa de aparecimento de raízes laterais e a área de superfície de raiz (DIDONET et al., 1996; GITTI et al., 2012; RAMPIM et al., 2012; DOURADO NETO et al., 2014; RODRIGUES et al., 2015).

A partir disso, há a necessidade de compor maior número de informações acerca dos efeitos da interação trigo - A. brasilense sobre a germinação e desenvolvimento inicial da cultura do trigo. Fatores como o pH da água de embebição, semelhando ao que ocorre com a solução do solo, podem afetar a atividade da bactéria, influenciando nos seus efeitos sobre as sementes e plântulas.

Cultura Agronômica, Ilha Solteira, v.26, n.4, p.694-704, 2017 
Assim, o objetivo do trabalho foi avaliar a qualidade fisiológica de sementes de trigo submetidas a inoculação com $A$. brasilense, bem como, apontar o efeito do $\mathrm{pH}$ da água de embebição sobre a germinação e a atividade da bactéria durante o desenvolvimento inicial de plântulas.

\section{MATERIAL E MÉTODOS}

O estudo foi conduzido no Laboratório Didático e de Pesquisa em Sementes (LDPS) da Universidade Federal de Santa Maria (UFSM). O período de implantação e avaliação dos experimentos compreendeu os meses de maio a julho de 2016. Buscando caracterizar possíveis variações no vigor inicial das sementes foram utilizadas sementes de dois lotes obtidos da colheita do ano 2015 em uma empresa situada no município de Santo Augusto, RS, Brasil. A cultivar de trigo utilizada foi a 'TBioSinuelo' (BIOTRIGO GENÉTICA), ciclo médio-tardio, estatura de planta média-baixa. Anteriormente a implantação dos experimentos foi realizada a caracterização física dos lotes de sementes pelo teor de água por meio do método da estufa com circulação forçada de ar $\left(105^{\circ} \mathrm{C} \pm 3^{\circ} \mathrm{C}\right.$ por 24 horas) e a massa de mil sementes, sendo os resultados expressos em porcentagem de umidade e gramas 1000 sementes $^{-1}$, respectivamente (BRASIL, 2009).

Foi adotado o delineamento inteiramente casualizado, com arranjo em esquema fatorial $(2 \times 2 \times 2)$ e oito repetições. No primeiro fator foram alocados os lotes de sementes, no segundo fator a inoculação e no terceiro fator os pH's da solução de embebição de sementes. Os lotes foram caracterizados em lote 1 e lote 2 . O inoculante utilizado composto por bactérias do gênero Azospirillum brasilense, estirpes $\mathrm{Ab}-\mathrm{V}_{5}$ e $\mathrm{Ab}-\mathrm{V}_{6}$ (AzoTotal ${ }^{\circledR}$ gramíneas) com garantias de $2 \times 10^{8} \mathrm{UFC} \mathrm{mL}^{-1}$ na dose de $0,002 \mathrm{~L} \mathrm{~kg}^{-1}$ de sementes. $\mathrm{O} \mathrm{pH}$ das soluções de embebição testados, $\mathrm{pH}$ 5,0 e pH 7,0, foram aferidos com aparelho pHmetro digital de bancada M300; com a destilação e deionização pelos aparelhos de uso da rotina do laboratório, obteve-se a solução de pH ácido (5); foi feita a adição e mistura de cloreto de sódio $(\mathrm{NaCl}, 1 \mathrm{~N})$ até a estabilização da solução em pH neutro (7).

Foram medidas as características fisiológicas que reportam à qualidade de sementes: Primeira contagem do teste de germinação (PCG) e germinação (GERM): foram utilizadas oito repetições de 50 sementes para cada tratamento, distribuídas em rolos de papel germitest umedecidos com 2,5 vezes a massa do papel seco e mantidos em germinador regulado a $25^{\circ} \mathrm{C}$. As avaliações foram realizadas aos quatro e oito dias após início do teste para PCG e GERM, respectivamente (BRASIL, 2009). Os resultados foram expressos em porcentagem de plântulas normais; Comprimento de parte aérea (CPA) de plântula e radícula $(\mathrm{CR})$ : determinado conjuntamente com o teste de germinação, selecionando-se 10 plantas normais após quatro dias da instalação do teste. Para as aferições foi utilizada uma régua graduada. Os resultados serão expressos em $\mathrm{cm}_{\text {plântula }}{ }^{-1}$; Matéria seca de plântulas (MSP): mensurada conjuntamente com o teste de germinação, selecionando-se 10 plantas normais após quatro dias da instalação do teste. Para aferição da massa as plântulas foram

Cultura Agronômica, Ilha Solteira, v.26, n.4, p.694-704, 2017 
levadas à estufa e desidratadas a $70^{\circ} \mathrm{C}$ durante 48 h. A matéria seca das plântulas foi determinada pela divisão da massa total pelo número de plântulas utilizadas.

Os dados foram submetidos ao teste das pressuposições do modelo matemático, sendo necessária a transformação angular $\left(\operatorname{Arco} \operatorname{seno} \sqrt{\frac{\mathbf{x}}{\mathbf{1 0 0}}}\right.$ ) para as variáveis PCG e GERM. Foi realizada a análise de variância pelo teste $\mathrm{F}(\alpha \leq 0,05)$, procedendo-se o teste complementar de separação de médias Skott-Knott $(\alpha \leq 0,05)$. Para as análises foi utilizado o software estatístico Sisvar $^{\circledR}$ (FERREIRA, 2011).

\section{RESULTADOS E DISCUSSÃO}

As características dos lotes de sementes - teor de água e massa de mil sementes - não apresentaram diferenças estatísticas. O lote 1 apresentou média de 33,4 g 1000 sementes $^{-1}$ e umidade de $13,1 \%$ e o lote $02,35,8$ g e $13,2 \%$, respectivamente. A germinação não foi influenciada pelos fatores lote e $\mathrm{pH}$ da solução (Tabela 1). Provavelmente, em função a elevada qualidade fisiológica inicial das sementes utilizadas, não foi constatada respostas para germinação (MOTTA; SILVA, 1999).

Sementes inoculadas com A. brasilense apresentaram menor percentual de germinação em relação aos tratamentos sem inoculação. As plântulas oriundas de sementes não inoculadas apresentaram maior comprimento radicular $(6,9 \mathrm{~cm})$ em relação às inoculadas $(4,7 \mathrm{~cm})$, bem como, sementes embebidas por solução pH $7(6,3 \mathrm{~cm})$ deram origem a plântulas com maior desenvolvimento radicular em relação ao observado sob pH $5(5,3 \mathrm{~cm})$.

Esse comportamento quanto a germinação das sementes em função da inoculação contraria os resultados obtidos por Kerbauy (2008) e Rampim et al. (2012), onde não foram observadas diferenças entre sementes de trigo inoculadas em relação às não inoculadas com a bactéria e, ao obtidos por Karthikeyan et al. (2007), onde foi observado incremento no percentual de germinação de sementes de arroz em função da inoculação com a bactéria. Uma possível justificativa para a resposta contraditória pode estar ligada ao fato de as bactérias se associarem às plantas após o início do desenvolvimento radicular, não influenciando ou interferindo na germinação das sementes em trigo (RAMPIM et al., 2012). Por outro lado, o conteúdo endógeno de $\mathrm{GA}_{3}$ das sementes trigo mais o aporte externo dado pelas bactérias pode ter resultado em uma concentração excessiva do fitohormônio nas sementes, resultando em queda no percentual de germinação obtido quando inoculadas (TAIZ; ZEIGER, 2013).

Com relação ao vigor, na primeira contagem de germinação (Tabela 2) sementes do lote 1 apresentaram maior percentual de germinação na presença da bactéria, o que salienta a interação inoculação x lote sobre as respostas apresentadas. Em relação ao pH da água de embebição, com a bactéria, sementes embebidas em água com pH 7 apresentaram valores mais elevados de germinação, sendo que, sem a bactéria, não foi possível observar diferença entre os potenciais testados.

Cultura Agronômica, Ilha Solteira, v.26, n.4, p.694-704, 2017 
Tabela 1. Resumo da análise de variância e médias das fontes de variação em função da inoculação com Azospirillum brasilense, pH da água de embebição e lotes de sementes de trigo.

\begin{tabular}{|c|c|c|c|c|c|c|}
\hline FV & GL & $\mathrm{G}$ & PCG & $\mathrm{CR}$ & CPA & MSP \\
\hline Inoculação & 1 & $189,1^{* *}$ & $1870,6^{* *}$ & $78,3^{* *}$ & $11,5^{* *}$ & $0,001^{\mathrm{ns}}$ \\
\hline Lote & 1 & $33,1^{\mathrm{ns}}$ & $7,6^{\mathrm{ns}}$ & $0,4^{\mathrm{ns}}$ & $1,0^{\mathrm{ns}}$ & $0,0001^{\mathrm{ns}}$ \\
\hline $\mathrm{pH}$ & 1 & $52,6^{\mathrm{ns}}$ & $370,6^{* *}$ & $15,4^{* *}$ & $5,9^{* *}$ & $0,005^{*}$ \\
\hline Inoculação x Lote & 1 & $0,1^{\mathrm{ns}}$ & $390,1^{* *}$ & $0,2^{\mathrm{ns}}$ & $3,4^{* *}$ & $0,001^{\mathrm{ns}}$ \\
\hline Inoculação x pH & 1 & $3,1^{\mathrm{ns}}$ & $189,6^{*}$ & $0,4^{\mathrm{ns}}$ & $0,01^{\mathrm{ns}}$ & $0,002^{\mathrm{ns}}$ \\
\hline Lote $\mathrm{x}$ pH & 1 & $14,1^{\mathrm{ns}}$ & $22,6^{\mathrm{ns}}$ & $0,3^{\text {ns }}$ & $0,2^{\mathrm{ns}}$ & $0,007^{*}$ \\
\hline Inoculação x Lote x pH & 1 & $0,1^{\mathrm{ns}}$ & $7,6^{\mathrm{ns}}$ & $1,0^{\mathrm{ns}}$ & $0,002^{\mathrm{ns}}$ & $0,0009^{\text {ns }}$ \\
\hline Erro & 56 & 13,9 & 38,9 & 0,3 & 0,33 & 0,001 \\
\hline Total & 63 & & & & & \\
\hline $\mathrm{CV} \%$ & & 4,2 & 8,1 & 9,1 & 14,6 & 11,1 \\
\hline Média geral & & 89,3 & 76,6 & 5,8 & 4,0 & 0,3 \\
\hline \multicolumn{7}{|l|}{ Inoculação de sementes } \\
\hline Com & & $87,6 \mathrm{~b}$ & 71,2 & $4,7 \mathrm{~b}$ & 3,5 & 0,29 \\
\hline Sem & & $91,1 \mathrm{a}$ & 82,0 & $6,9 \mathrm{a}$ & 4,4 & 0,28 \\
\hline \multicolumn{7}{|l|}{ Lote } \\
\hline 01 & & 88,6 & 76,2 & 5,9 & 3,8 & 0,29 \\
\hline 02 & & 90,1 & 77,0 & 5,7 & 4,1 & 0,29 \\
\hline \multicolumn{7}{|l|}{ pH do solo } \\
\hline 5,0 & & 88,4 & 74,2 & $5,3 \mathrm{~b}$ & $3,7 \mathrm{~b}$ & 0,30 \\
\hline 7,0 & & 90,2 & 79,0 & $6,3 \mathrm{a}$ & $4,3 \mathrm{a}$ & 0,28 \\
\hline
\end{tabular}

${ }^{*}{ }^{* * *}$ significativo pelo teste $\mathrm{F}$ a $5 \%$ e $1 \%$ de probabilidade de erro, respectivamente; ${ }^{\text {ns }}$ não significativo; fonte de variação (FV); grau de liberdade (GL); coeficiente de variação (CV). Variáveis: germinação (G, \%), primeira contagem do teste de germinação (PCG, \%), comprimento de radícula $(\mathrm{CR}, \mathrm{cm})$ e de parte aérea de plântulas (CPA, cm), matéria seca de plântulas (MSP, g); Médias seguidas pela mesma letra não diferem estatisticamente entre si, pelo teste de Skott-Knott $(\alpha \leq 0,05)$.

Altamente vulnerável a estresses ambientais, o $A$. brasilense pode ter sido influenciado pelo $\mathrm{pH}$ nas condições de estudo, embora não tenham sido realizadas contagens bacterianas na planta para sustentar esta afirmação. É notável que, apesar de o pH 5 encontrar-se próximo a faixa considerada adequada para a cultura do trigo $(5,5$ a 6,5$)$, está bem abaixo da faixa considerada ideal $(6$ a 6,5) para a máxima atividade microbiana no solo (COELHO; VERLENGIA, 1973). Segundo Cardoso et al. (1992) sob valores extremos de pH o crescimento destes microorganismos no solo pode ser prejudicado não apenas pelo efeito direto da elevada concentração de íons $\mathrm{H}^{+}$, mas também pela penetração de compostos tóxicos presentes no meio no interior das células microbianas.

A resposta positiva à inoculação pode ser atribuída a outros fatores além da produção de substâncias promotoras do crescimento. Entre elas a alteração da atividade metabólica através de efeitos sobre as membranas celulares (BASHAN et al., 2004). No entanto, apesar

Cultura Agronômica, Ilha Solteira, v.26, n.4, p.694-704, 2017 
das vantagens que as bactérias diazotróficas proporcionam às plantas sua eficiência a campo é prejudicada, na maioria das vezes, em função de estarem associadas livremente à planta, tornando-se muito vulneráveis ao ambiente (SABINO et al., 2012).

Dados semelhantes foram encontrados por Kannan e Ponmurugan (2010) e Araújo et al. (2010), onde as bactérias diazotróficas aumentaram a velocidade de germinação, sobressaindo-se em comparação à ausência da bactéria. Porém, como a qualidade do lote não é uma grandeza diretamente mensurável, visto que, não é transcrita com base em apenas uma avaliação individual de uma característica do lote, esta poderia ser insuficiente para discriminar a qualidade deste lote (LORENTZ NUNES, 2013).

Tabela 2. Primeira contagem de germinação (PCG, \%) em função da inoculação com $A$. brasilense, $\mathrm{pH}$ da água de embebição e lotes de sementes de trigo.

\begin{tabular}{ccc}
\hline Tratamentos & Com & Sem \\
\hline Lote & & \\
01 & $84 \mathrm{aA}$ & $68 \mathrm{aB}$ \\
02 & $79 \mathrm{bA}$ & $74 \mathrm{aA}$ \\
$\mathrm{pH}$ do solo & & \\
5,0 & $77 \mathrm{bA}$ & $70 \mathrm{aB}$ \\
7,0 & $86 \mathrm{aA}$ & $71 \mathrm{aB}$
\end{tabular}

*Médias seguidas pela mesma letra não diferem estatisticamente entre si, pelo teste de Skott-Knott $(\alpha \leq 0,05)$; Letras minúsculas são observadas na coluna e letras maiúsculas são observadas na linha.

Para o comprimento de parte aérea de plântulas (Tabela 3), sementes embebidas com água a pH $7(4,3 \mathrm{~cm})$ deram origem a plântulas com maior crescimento em relação ao observado em condições de pH $5(3,7 \mathrm{~cm})$. Estes resultados contrariam aos obtidos por Wagner Junior et al. (2006), onde o fator pH da água de embebição e a interação pH x substrato não interferiram sobre as variáveis analisadas. Os valores de $\mathrm{pH}$ estudados $(3,0 \mathrm{a}$ $7,0)$ por estes autores não tiveram ação sobre a germinação das sementes e desenvolvimento inicial das plântulas.

Tabela 3. Comprimento de parte aérea de plântulas $(\mathrm{CPA}, \mathrm{cm})$ em função da inoculação com A. brasilense e lotes de sementes de trigo.

\begin{tabular}{ccc}
\hline \multirow{2}{*}{ Lote } & Com & Sem \\
\hline 01 & $3,2 \mathrm{bB}$ & $4,5 \mathrm{aA}$ \\
02 & $3,9 \mathrm{aA}$ & $4,3 \mathrm{aA}$ \\
\hline
\end{tabular}

${ }^{*}$ Médias seguidas pela mesma letra não diferem estatisticamente entre si, pelo teste de Skott-Knott $(\alpha \leq 0,05)$; Letras minúsculas são observadas na coluna e letras maiúsculas são observadas na linha.

Com relação à inoculação com $A$. brasilense, a presença da bactéria não agregou efeito sobre as sementes provenientes do lote 2 . Não foi possível observar diferença entre sementes inoculadas e não inoculadas. Para sementes do lote 1, estas apresentaram maior comprimento de parte aérea de plântulas quando não inoculadas.Diferenças entre lotes de 
sementes quanto ao seu potencial fisiológico podem ter como fonte, dentre outros fatores, a temperatura e período de permanência das sementes a campo, fatores que podem influenciar sobre o comportamento das sementes em cada teste (MARCOS FILHO, 2005).

Neste estudo, a A. brasilense proporcionou valores inferiores ao obtidos em sua ausência para GER e CR, independentemente do lote. Esses resultados são relevantes por contrariarem os resultados obtidos por Kannan e Ponmurugan (2010), Araújo et al. (2010), Sabino et al. (2012) e Rampim et al. (2012), onde houve interferência positiva das bactérias diazotróficas no desenvolvimento inicial de plântulas. Há a necessidade de mais trabalhos envolvendo A. brasilense, como, por exemplo, a utilização de concentrações diferenciadas da bactéria na inoculação e estirpes diferentes.

Tabela 4. Massa seca de plântulas (MSP, g) em função do pH da água de embebição e lotes de sementes de trigo.

\begin{tabular}{ccc}
\hline Lote & 5,0 & 7,0 \\
\hline Lote 01 & $0,28 \mathrm{bA}$ & $0,29 \mathrm{aA}$ \\
Lote 02 & $0,31 \mathrm{aA}$ & $0,29 \mathrm{aA}$ \\
\hline
\end{tabular}

"Médias seguidas pela mesma letra não diferem estatisticamente entre si, pelo teste de Skott-Knott $(\alpha \leq 0,05)$; Letras minúsculas são observadas na coluna e letras maiúsculas são observadas na linha.

Quanto a matéria seca de plântulas (Tabela 4), plântulas obtidas de sementes do lote 2 quando submetidas ao crescimento em solução com pH $5(0,31 \mathrm{~g})$ apresentaram maior biomassa seca em relação à obtida no lote $1(0,28 \mathrm{~g})$. Estes resultados salientam o vigor mais elevado que foi expresso pelo lote 2 em comparação ao lote 1, quando submetido aos testes utilizados. Durante o teste, sementes vigorosas proporcionam maior transferência de massa seca de seus tecidos de reserva para o eixo embrionário durante a fase de germinação, dando origem a plântulas com maior peso, em função do maior acúmulo de matéria seca. Estas plântulas, provavelmente, terão maiores possibilidades de emergir e assim produzir plantas normais em condições adversas de campo (KRZYZANOWSKI et al., 1999).

\section{CONCLUSÃO}

A inoculação de sementes com Azospirillum brasilense, estirpes Ab- $\mathrm{V}_{5}$ e Ab-V6, reduz o percentual de germinação do trigo.

Sementes embebidas em água com pH 7 apresentam maior vigor de plântulas quando inoculadas com Azospirillum brasilense, estirpes $\mathrm{Ab}-\mathrm{V}_{5}$ e $\mathrm{Ab}-\mathrm{V}_{6}$.

\section{REFERÊNCIAS BIBLIOGRÁFICAS}

ASSOCIAÇÃO BRASILEIRA DE SEMENTES E MUDAS - ABRASEM. Anuário 2014. Brasília: Ministério da Agricultura, Pecuária e Abastecimento, 2014. 52 p. Disponível em:

Cultura Agronômica, Ilha Solteira, v.26, n.4, p.694-704, 2017 
http://www.abrasem.com.br/wp-content/uploads/2013/09/Anu\%C3\%A1rio-Abrasem2014.pdf . Acesso em: 21 abr. 2017.

AlMEIDA, A. S.; CARVAlHO, I.; DEUNER, C.; TILlMANN, M. A. A.; VILlELA, F. A. Bioativador no desempenho fisiológico de sementes de arroz. Revista Brasileira de Sementes, Londrina, v. 33, n. 3, p.501-510, 2011. Disponível em: http://submission.scielo.br/index.php/jss/article/view/37077/6749 . Acesso em: 20 abr. 2017

ARAÚJO, A. E. S.; ROSSETTO, C. A. V.; BALDANI, V. L. D.; BALDANI, J. I. Germinação e vigor de sementes de arroz inoculadas com bactérias diazostróficas. Ciência Agrotecnologia, Lavras, v. 34, n. 4, p.932-939, 2010. Disponível em: http://www.scielo.br/scielo.php?script=sci_arttext\&pid=S1413-70542010000400019 Acesso em: 10 abr. 2017.

BARBIERI, A. P. P.; MARTIN, T. N.; MERTZ, L. M.; NUNES, U. G.; CONCEIÇÃO, G. M. Redução populacional de trigo no rendimento e na qualidade fisiológica das sementes. Revista Ciência Agronômica, Fortaleza, v. 44, n. 4, p.724-731, 2013. Disponível em: http://ccarevista.ufc.br/seer/index.php/ccarevista/article/view/2215/854 . Acesso em: 10 jan. 2017.

BASHAN, Y.; HOLGUIN, G.; DE-BASHAN, L. E. Azospirillum-plant relations physiological, molecular, agricultural, and environmental advances (1997-2003). Canadian Journal of Microbiology, Ontario, v. 50, n. 8, p.521-577, 2004. Disponível em: https://www.ncbi.nlm.nih.gov/pubmed/15467782 . Acesso em: 13 jan. 2017.

BERGAMASCHI, C.; ROESCH, L. F. W.; QUADROS, P. D.; CAMARGO, F. A. O. Ocorrência de bactérias diazotróficas associadas a cultivares de sorgo forrageiro. Ciência Rural, Santa Maria, v. 37, n. 3, p.727-733, 2007. Disponível em: http://www.scielo.br/scielo.php?pid=S010384782007000300019\&script=sci_abstract\&tlng=pt . Acesso em: 10 jan. 2017.

BRASIL - Ministério da Agricultura, Pecuária e Abastecimento - MAPA. Regras para análises de sementes. Brasília: MAPA/ACS, 2009. 399 p. Disponível em: http://www.agricultura.gov.br/assuntos/insumos-agropecuarios/arquivos-publicacoesinsumos/2946_regras_analise_sementes.pdf . Acesso em: 13 jan. 2017.

CARDOSO, E. J. B. N.; TSAI, S. M.; NEVES, M. C. P. Microbiologia do solo. Campinas: Sociedade Brasileira de Ciência do Solo, 1992. 121 p.

CARVAlho, N. M.; NAKAGAWA, J. Sementes: Ciência, Tecnologia e Produção. Jaboticabal: FUNEP, 2012. 588 p.

COELHO, F. S.; VERLENGIA, F. Fertilidade do solo. 2. ed. Campinas: Instituto Campineiro de Ensino Agrícola, 1973. 384 p.

DIDONET, D. D.; RODRIGUES, O.; KENNER, M. H. Acúmulo de nitrogênio e de massa seca em plantas inoculadas com Azospirillum brasilense. Pesquisa Agropecuária Brasileira, Brasília, v. 31, n. 9, p.645-651, 1996. Disponível em: Cultura Agronômica, Ilha Solteira, v.26, n.4, p.694-704, 2017 
https://www.embrapa.br/busca-de-publicacoes/-/publicacao/104130/acumulo-de-nitrogenioe-de-massa-seca-em-plantas-de-trigo-inoculadas-com-azospirillum-brasilense . Acesso em: 14 jan. 2017.

DOURADO NETO, D.; DARIO, G. J. A.; BARBIERI, A. P. P.; MARTIN, T. N. Ação de bioestimulante no desempenho agronômico de milho e feijão. Biosciente Journal, Uberlândia, v. $\quad 30, \quad$ n. $\quad 1, \quad$ p.371-379, 2014. Disponível em: http://www.seer.ufu.br/index.php/biosciencejournal/article/view/18110/14549 . Acesso em: 11 jan. 2017.

\section{EMPRESA BRASILEIRA DE PESQUISA AGROPECUÁRIA - EMBRAPA. Informações}

Técnicas para trigo e triticale. Brasília: Embrapa, 2014. 229 p. (VIII Reunião da Comissão Brasileira de Pesquisa de Trigo e Triticale). Disponível em: https://www.embrapa.br/documents/1355291/1729833/2015-

inf+tecn+trigo+e+triticale.pdf/205d3919-c572-4410-bc4d-1499b94333ba . Acesso em: 13 jan. 2017.

FAVARATO, L. F.; ROCHA, V. S.; ESPINDULA, M. C.; SOUZA, M. A.; PAULA, G. S. Adubação nitrogenada e qualidade fisiológica de sementes de trigo. Bragantia, Campinas, v. $71, \quad$ n. $1, \quad$ p.371-379, 2012. Disponível em: http://www.scielo.br/pdf/brag/2012nahead/aop_1053_12.pdf . Acesso em: 16 mar. 2017.

FERREIRA, D. F. Sisvar: A computer statistical analysis system. Ciência e Agrotecnologia, Lavras, v. 35, n. 6, p.1039-1042, 2011. Disponível em: http://www.scielo.br/scielo.php?script=sci_arttext\&pid=S1413-70542011000600001 Acesso em: 19 mar. 2017.

GITTI, D. C.; ARF, O.; PORTUGAL, J. R.; CORSINI, D. C. D. C.; RODRIGUES, R. A. F.; KANEKO, F. H. Coberturas vegetais, doses de nitrogênio e inoculação de sementes com A. brasilense em arroz de terras altas no sistema plantio direto. Bragantia, Campinas, v. 71, n. 4, p.509-517, 2012. Disponível em: http://www.scielo.br/scielo.php?pid=S000687052012000400009\&script=sci_abstract\&tlng=pt . Acesso em: 29 mar. 2017.

KANNAN, T.; PONMURUGAN, P. Response of Paddy (Oryza sativa L.) Varieties to Azospirillum brasilense Inoculation. Journal of Phytology, Georgetown, v. 2, n. 6, p.8-13, 2010. Disponível em: http://scienceflora.org/journals/index.php/jp/article/view/2136 . Acesso em: 29 abr. 2017.

KARTHIKEYAN, B.; JALEEL, C. A.; GOPI, R.; DEIVEEKASUNDARAM, M. Alterations in seedling vigour and antioxidant enzyme activities in Catharanthus roseus under seed priming with native diazotrophs. Journal of Zhejiang University, Hangzhou, v. 8, p.453-457, 2007. Disponível em: https://www.ncbi.nlm.nih.gov/pubmed/17610323 . Acesso em: 19 fev. 2017.

KERBAUY, G. B. Fisiologia Vegetal. Guanabara: Rio de Janeiro, 2008. 431 p.

Cultura Agronômica, Ilha Solteira, v.26, n.4, p.694-704, 2017 
LACA-BUENDIA, J. P. Efeito de doses de reguladores de crescimento no algodoeiro. Revista Brasileira de Fisiologia Vegetal, Campinas, v. 1, n. 1, p.109-113, 1989.

LORENTZ, L. H.; NUNES, U. R. Relações entre medidas de qualidade de lotes de sementes de arroz. Revista Ciência Agronômica, Fortaleza, v. 44, n. 4, p.798-804, 2013. Disponível em: http://ccarevista.ufc.br/seer/index.php/ccarevista/article/view/2258/863 . Acesso em: 19 fev. 2017.

MARCOS FILHO, J. Fisiologia de sementes de plantas cultivadas. Piracicaba: FEALQ, 2005. $495 \mathrm{p}$.

MOTTA, C. A. P.; SILVA, W. R. Desempenho fisiológico e sanidade de sementes de trigo submetidas a tratamentos de hidratação/desidratação. Scientia Agrícola, Piracicaba, v. 56, n. $3, \quad$ p.571-580, $1999 . \quad$ Disponível em: http://www.scielo.br/scielo.php?script=sci_arttext\&pid=S0103-90161999000300009 Acesso em: 19 fev. 2017.

KRZYZANOWSKI, F. C.; VIEIRA, R. D.; FRANÇA-NETO, J. B. (Ed.). Vigor de sementes: conceitos e testes. Londrina: ABRATES, 1999. 218 p.

PEREIRA, L. C.; PIANA, S. C.; BRACCINI, A. L.; GARCIA, M. M.; FERRI, G. C.; FELBER, P. H.; MARTELI, D. C. V.; BIANCHESSI, P. A.; DAMETTO, I. B. Rendimento do trigo (Triticum aestivum) em resposta a diferentes modos de inoculação com Azospirillum brasilense. Revista de Ciências Agrárias, Recife, v. 40, n. 1, p.106-114, 2017.

https://www.researchgate.net/publication/313903770_Rendimento_do_trigo_Triticum_aesti vum_em_resposta_a_diferentes_modos_de_inoculacao_com_Azospirillum_brasilense Acesso em: 09 fev. 2017.

RAMPIM, L.; RODRIGUES-COSTA, A.C.P.; NACKE, H.; KLEIN, J.; GUIMARÃES, V.F. Qualidade fisiológica de sementes de três cultivares de trigo submetidas à inoculação e diferentes tratamentos. Revista Brasileira de Sementes, Londrina, v. 34, n. 4, p.678 - 685, 2012. Disponível em: http://www.scielo.br/scielo.php?script=sci_arttext\&pid=S010131222012000400020 . Acesso em: 02 fev. 2017.

REIS, D. F. A.; COSTA, E. M. M; GONÇALVEZ, J. R; CIDES, M. F. B.; RODRIGUES, T. M. A. Influência da luz na germinação das sementes de rabanete (Raphanus sativus L.). AdolesCiência - Revista Júnior de Investigação, Bragança, v. 3, n. 1, p.79-84, 2014. Disponível em: https://bibliotecadigital.ipb.pt/bitstream/10198/12957/1/159-765-1PB\%20\%281\%29.pdf . Acesso em: 03 fev. 2017.

RODRIGUES, L. A.; BATISTA, M. S.; ALVAREZ, R. C. F.; LIMA, S. F.; ALVES C. Z. Avaliação fisiológica de sementes de arroz submetidas a doses de bioestimulante. Nucleus, Ituverava, v. 12, n. 1, p.207-214, 2015. Disponível em: http://www.nucleus.feituverava.com.br/index.php/nucleus/article/view/1376/1790 . Acesso em: 07 mar. 2017.

Cultura Agronômica, Ilha Solteira, v.26, n.4, p.694-704, 2017 
SABINO, D. C. C.; FERREIRA, J. S.; GUIMARÃES, S. L.; BALDANI, V. L. D. Bactérias diazostróficas como promotoras do desenvolvimento inicial de plântulas de arroz. Enciclopédia Biosfera, Goiânia, v. 8, n. 15, p.2337-2345, 2012. Disponível em: http://www.conhecer.org.br/enciclop/2012b/ciencias\%20biologicas/bacterias.pdf . Acesso em: 07 abr. 2017.

SIlVA, J. A. G.; ARENHARDT, E. G.; KRÜGER, C. A. M. B.; LUCCHESE, O. A.; METZ, M.; MAROLLI, A. Expressão dos componentes de produtividade do trigo pela classe tecnológica e aproveitamento do nitrogênio. Brasileira Engenharia Agrícola Ambiental, Campina Grande, v. 19, n. 1, p.27-33, 2015. Disponível em: http://www.scielo.br/scielo.php?script=sci_arttext\&pid=S1415-43662015000100027

Acesso em: 07 abri. 2017.

TAIZ, L.; ZEIGER, E. Fisiologia Vegetal. 5. ed. Porto Alegre: Artmed Editora, 2013. 820 p.

VIEIRA, R. D.; CARVALHO, N. M. Testes de vigor em sementes. Jaboticabal: UNESP, 1994. $164 \mathrm{p}$.

ZADOKS, J. C., CHANG, T. T., KONZAK, C. F. A decimal code for growth stages of cereals. Weed Research, Ithaca, v. 14, n. 1, p.415-421, 1977. Disponível em: http://old.ibpdev.net/sites/default/files/zadoks_scale_1974.pdf . Acesso em: 04 mar. 2017.

WAGNER JÚNIOR, A.; SANTOS, C. E. M.; SILVA J. O. C.; ALEXANDRE, R. S.; NEGREIROS, J. R. S.; PIMENTEL, L. D.; ÁlVARES, V. S.; BRUCKNER, C. H. Influência do $\mathrm{pH}$ da água de embebição das sementes e do substrato na germinação e desenvolvimento inicial do maracujazeiro doce. Revista Brasileira de Agrociência, Pelotas, 12, n. 2, p.231-235, 2006. Disponível em: https://periodicos.ufpel.edu.br/ojs2/index.php/CAST/article/viewFile/4540/3398 . Acesso em: 04 fev. 2017. 